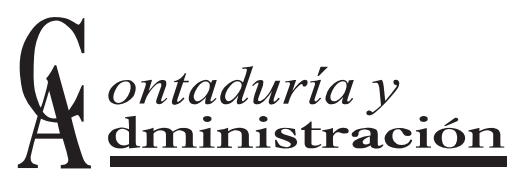

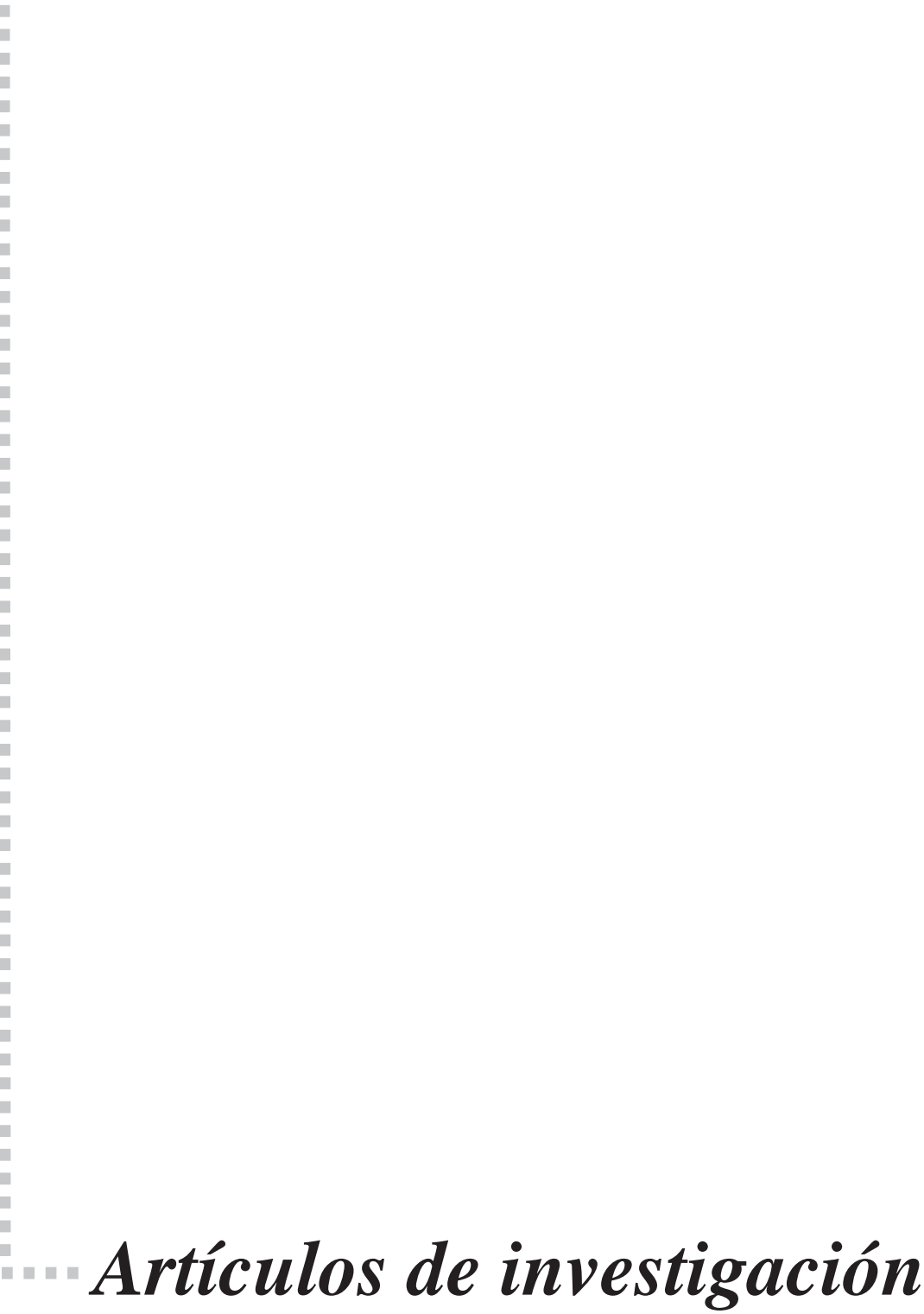




\title{
Competencias de los auditores gubernamentales chilenos para la obtención de evidencia electrónica de auditoría
}

\author{
Daniella Caldana \\ Ricardo Correa \\ Héctor Ponce*
}

\section{Resumen}

En este artículo se presentan los resultados de un trabajo de investigación cuyo objetivo fue determinar las competencias con que cuentan los auditores internos gubernamentales chilenos para la obtención de evidencia electrónica de auditoría confiable y de calidad que permita respaldar los hallazgos y conclusiones contenidas en el informe de auditoría. Para ello se desarrolló un modelo de competencias que contiene la definición de competencias conceptuales y procedimentales, requeridas para obtener evidencia electrónica de auditoría. La definición de las competencias estuvo basada en los atributos técnicos asociados a la evidencia electrónica y en los criterios de confiabilidad y calidad de la información en formato digital. Este modelo se usó para evaluar, mediante una investigación por encuesta, si los auditores poseían el conocimiento y las competencias específicas para trabajar con este tipo de evidencia. La población encuestada fue de 237 auditores empleados en servicio públicos pertenecientes a 9 ministerios. Un total de 197 personas respondió la encuesta, correspondiente al $83.1 \%$ de la población. Los resultados de la investigación demuestran que sólo un $8.1 \%$ de los auditores gubernamentales cuenta con las competencias para obtener evidencia electrónica de auditoría confiable y de calidad. Dado el acelerado desarrollo del gobierno electrónico en Chile, este estudio concluye en la necesidad urgente de que los auditores gubernamentales adquieran competencias para obtener evidencia electrónica; de lo contrario, el riesgo de auditoría podría incrementarse sustancialmente.

Palabras clave:competencia, evidencia electrónica de auditoría, evidencia en papel, e-gobierno, e-auditoría.

Fecha de recepción: 04/12/2006

Fecha de aceptación: 11/05/2007 * Profesores del Departamento de Contabilidad y Auditoría, Universidad de Santiago de Chile, USACH.
Correo electrónico: hponce@usach.cl 
Daniella Caldana, Ricardo Correa y Héctor Ponce

\title{
The Competencies of Chilean Governmental Auditors for Collecting Audit. Electronic Evidence
}

\begin{abstract}
This paper reports the results of a research study whose objective was to determine the competencies that Chilean government auditors have to obtain reliable and quality audit electronic evidence in order to support the findings and conclusions contained on the audit report. For this, a competency model was developed which contains the definition of knowledge and skills required to obtain audit electronic evidence. The establishment of the required competencies was based on the technical attributes associated with audit electronic evidence and reliability and quality criteria of digital information. This model was used to assess, through a survey research, if auditors possessed the specific knowledge and skills to work with this type of evidence. The population was constituted by 237 auditors employed by public service departments belonging to 9 ministries. The survey was responded by 197 individuals, representing $83.1 \%$ of the population. The research findings indicate that only $8.1 \%$ of the population has the competencies to obtain reliable and quality audit electronic evidence. Given the rapid development of electronic government in Chile, this study concludes on the urgent need for government auditors to develop competencies to work with audit electronic evidence, otherwise, the audit risk could substantially be increased.
\end{abstract}

Keywords: competency, audit electronic evidence, paper based evidence, e-government, e-auditing.

\section{Introducción}

partir del año 2001, el Gobierno de Chile le brinda un carácter prioritario a la moAdernización electrónica del aparato público, con el establecimiento de proyectos transversales que incluyen a varios sectores de la administración pública, como es la intranet del Estado, Portal de Chilecompras, Sistema de Gestión Financiera del Estado (SIGFE), ventanilla única del consumidor y proyectos sectoriales, como factura electrónica, nuevo sistema de identificación, emisión de certificados por Internet, entre otros (Chateau, et al., 2003).

Una muestra del avance en esta materia es que uno de los organismos públicos señeros en gobierno electrónico, el Servicio de Impuestos Internos (sII), informó que al concluir la Operación Renta 2006 se alcanzó un récord de 97.04\% de declaraciones por Internet, equivalente a 2,068,001 documentos recepcionados (sII, 2006, mayo 10). 
Competencias de los auditores gubernamentales chilenos para la obtención de evidencia electrónica...

Además, diversos índices demuestran que Chile progresa aceleradamente en el desarrollo del gobierno electrónico. Así lo confirmó el Reporte "Global E-Government, 2006” que sitúa a Chile en el lugar número 18 del ranking, entre 198 naciones del mundo (West, 2006). En tanto, el informe de la Naciones Unidas "Global E-Government Readiness Report 2005” ubica a Chile en el lugar 22 entre 179 países y en el primer lugar en América Central y del Sur (United Nations, 2005).

El desarrollo del gobierno electrónico y los cambios normativos que se han realizado son antecedentes importantes que pronostican un uso más frecuente por organismos del Estado de documentación electrónica y el respaldo de operaciones y transacciones en este mismo medio informático. Por lo tanto, los auditores que se desempeñan en los servicios públicos deberán diseñar y aplicar procedimientos para obtener evidencia electrónica confiable y de calidad de actos y transacciones en forma distinta a como lo harían si la documentación se encontrara exclusivamente en papel.

En este contexto, el tema de la evidencia electrónica de auditoría es, sin duda, un nuevo actor relevante que obliga a quienes se desempeñan en esta disciplina a poseer competencias para obtener evidencias en forma confiable y completa que respalde los hallazgos y conclusiones contenidos en el informe de auditoría. En este mundo "sin papeles" es clave, entonces, que los auditores internos, que son los encargados de examinar y verificar la integridad de las operaciones y transacciones electrónicas, desarrollen competencias en el manejo de documentos electrónicos.

De esta forma, la pregunta de investigación que dio origen al proyecto de investigación, cuyos resultados se presentan en este artículo, es la siguiente: ¿Cuentan los auditores internos de sector gubernamental chileno con las competencias para obtener evidencia electrónica de auditoría confiable y de calidad? Para responder se desarrolló un proyecto de investigación, a través de un diseño por encuesta, cuyo objetivo principal fue determinar si los auditores internos del sector gubernamental identifican las diferencias que el soporte en medios electrónicos produce en términos de evidencia de auditoría y qué competencias específicas poseen en la actualidad para enfrentar estas diferencias. Los resultados de dicha investigación se presentan en las siguientes secciones.

\section{Marco conceptual}

La evidencia de auditoría es la información que obtiene el auditor para extraer conclusiones en las cuales sustenta su opinión. La evidencia de auditoría, de acuerdo a Valderrama (1998: 217) equivale a: 
"La convicción que le asiste al auditor de que una cosa es tal cual como él la ha percibido, luego de practicar el examen analítico de dicha cosa, mediante la aplicación de procedimientos que estimó más adecuados al objetivo perseguido.”

La evidencia obtenida por el auditor debe ser competente y suficiente, considerándose como tal cuando cumple con las características de relevancia, autenticidad, verificabilidad, confiabilidad y neutralidad (Poblete, 1998).

Para que la evidencia de auditoría sea aceptable debe ser confiable. La confiabilidad se define por criterios relacionados con la fuente (externa e interna) y forma como se obtiene (visual, documentos u oral). La obtención de evidencia suficiente y competente en la auditoría es afectada por factores como la naturaleza y nivel del riesgo de auditoría, la materialidad de la partida o transacción que se examina, la experiencia obtenida en auditorías previas y la fuente y confiabilidad de información disponible.

La creciente tendencia a los ambientes sin papel (ejemplo: comercio y gobierno electrónicos) genera un nuevo contexto para los auditores, quienes deben recopilar crecientemente información electrónica como evidencia de auditoría. La evidencia electrónica de auditoría es información creada, transmitida, procesada, registrada y/o mantenida electrónicamente, que apoya el contenido de un informe de auditoría. Los documentos electrónicos pueden tomar formas como texto, imágenes, audio, video y otros. La evidencia de auditoría electrónica es información digital que cuenta con una estructura lógica que está separada de la información (Esmond \& Lavigne, 2003).

Además de evaluar la confiabilidad de la evidencia, el auditor debe examinar la disponibilidad de la evidencia para propósitos de auditoría. La suficiencia y propiedad de la información electrónica de auditoría deben ser evaluadas considerando los riesgos específicos del uso de tal evidencia.

Durante esta investigación se utilizó como base el trabajo desarrollado por The Canadian Institute of Chartered Accountants (CICA). De acuerdo a estudios de este Instituto, los atributos de la evidencia electrónica de auditoría son básicamente cuatro (Esmond \& Lavigne, 2003).

a) Información digital: La evidencia de auditoría electrónica es información en formato digital. Se requieren software y hardware apropiados para leer y entender la información.

b) Migración de los datos: La información electrónica no está asociada con un medio físico permanente; la migración de datos se puede hacer fácilmente de un medio electrónico a otro. 
c) Estructura lógica de la información: La estructura lógica de un documento en papel es parte integrante de un documento y contribuye a su autentificación. La estructura de la información electrónica es definida por códigos y registros establecidos en este formato.

d) Metadatos: Un documento en papel contiene información en el contexto del documento que puede incluir los datos y lugar de su creación, envío y recepción e información del autor. Un metadato no es una parte integrante de un documento electrónico, pero contiene información del origen y destinación de la información electrónica y las fechas en que ha sido enviado y recibido.

Para el Canadian Institute of Chartered Accountans (CICA), la función de la evidencia en soporte electrónico es la misma que la tradicional, esto es, respaldar hallazgos y conclusiones contenidas en el informe de auditoría. Sin embargo, distingue ocho elementos que diferencian la evidencia documental en papel con aquélla en formato electrónico; esta investigación ha agregado uno más, referido al almacenamiento de los datos, por su importancia para el gobierno electrónico (CICA, 2003).

Tabla 1

Evidencia en papel versus evidencia electrónica (CICA, 2003)

\begin{tabular}{|c|c|c|}
\hline Atributo & $\begin{array}{l}\text { Evidencia de auditoría tradicional } \\
\text { (documentos en papel) }\end{array}$ & Evidencia electrónica de auditoría \\
\hline Origen & $\begin{array}{l}\text { El origen se puede probar y establecer } \\
\text { fácilmente. }\end{array}$ & $\begin{array}{l}\text { El origen es difícil de establecer solamente examinando } \\
\text { la información electrónica; es necesario usar controles y } \\
\text { técnicas de seguridad para establecer autentificación y no } \\
\text { repudio del documento. }\end{array}$ \\
\hline Alteración & $\begin{array}{l}\text { Es difícil de alterarlo sin que sea } \\
\text { descubierto. }\end{array}$ & $\begin{array}{l}\text { Es imposible detectar alteraciones examinando sólo la } \\
\text { información electrónica. La integridad de ésta depende de la } \\
\text { calidad de los controles y las técnicas de seguridad. }\end{array}$ \\
\hline Aprobación & $\begin{array}{l}\text { Los documentos en papel muestran la } \\
\text { prueba de la aprobación en su cuerpo. }\end{array}$ & $\begin{array}{l}\text { La aprobación es muy difícil de establecer sólo examinando } \\
\text { la información electrónica, ella se determina usando } \\
\text { controles y técnicas de seguridad que permiten determinar } \\
\text { la autorización de la información. }\end{array}$ \\
\hline Completitud & $\begin{array}{l}\text { Todos los términos relevantes de una } \\
\text { transacción son usualmente incluidos en un } \\
\text { documento. }\end{array}$ & $\begin{array}{l}\text { Se contienen, a menudo, los términos relevantes de una } \\
\text { transacción en varios archivos o mensajes de datos. }\end{array}$ \\
\hline Lectura & No se necesita equipo especial. & $\begin{array}{l}\text { Varias tecnologías y equipos son necesarios para leer el } \\
\text { documento electrónico. }\end{array}$ \\
\hline Formato & Es parte integrante del documento. & Está separado de los datos y puede ser cambiado. \\
\hline $\begin{array}{l}\text { Almacenamiento o } \\
\text { Archivo }\end{array}$ & $\begin{array}{l}\text { Los documentos se mantienen de acuerdo } \\
\text { a las necesidades de la organización según } \\
\text { normas de sana administración. }\end{array}$ & $\begin{array}{l}\text { Los documentos se mantienen en un repositorio con } \\
\text { características especiales de seguridad, integridad y } \\
\text { disponibilidad definidas por la Ley. }\end{array}$ \\
\hline $\begin{array}{l}\text { Disponibilidad y } \\
\text { Accesibilidad }\end{array}$ & $\begin{array}{l}\text { No es usualmente una restricción durante } \\
\text { la auditoría. }\end{array}$ & $\begin{array}{l}\text { El registro de auditoría puede no estar disponible en el tiempo } \\
\text { de la auditoría y acceder a los datos puede ser difícil. }\end{array}$ \\
\hline \multirow{2}{*}{ Firma } & $\begin{array}{l}\text { La firma se puede autentificar con un simple } \\
\text { chequeo y comparación entre el documento } \\
\text { y la firma original. }\end{array}$ & $\begin{array}{l}\text { Se requieren las tecnologías apropiadas para emitir y revisar } \\
\text { una firma electrónica fiable. }\end{array}$ \\
\hline & Es igual para todo tipo de documento. & $\begin{array}{l}\text { Es distinta según sea el grado de importancia del documento } \\
\text { (Firma Electrónica Simple o Avanzada). }\end{array}$ \\
\hline
\end{tabular}


La evidencia electrónica, de acuerdo al modelo cicA, es considerada competente si puede establecerse la autenticación, integridad y autorización de la información y, dependiendo de la materialidad y uso de la misma, el no repudio de su origen y contenido (CICA, 2003). Estos cuatro criterios se consideran además criterios de confiabilidad ya que confirman características de seguridad de la información. Al agregar los criterios complementarios de confidencialidad y accesibilidad estamos ante evidencia electrónica confiable y de calidad. A continuación se señala una definición básica de cada uno de estos criterios (Ford y Baum, 2001):

- Autenticación: Se refiere a la posibilidad de confirmar la identidad y origen de una persona o entidad al iniciar la información electrónica.

- Autorización: Se refiere al hecho de que la información electrónica ha sido creada, procesada, grabada, corregida, enviada, archivada, ingresada y destruida sólo por personas autorizadas y responsables.

- Integridad: Referida a la exactitud, validez, completitud y oportunidad de los datos. La integridad de un mensaje de datos se configura cuando la información contenida en él, ha permanecido completa y sin alteraciones desautorizadas de su contenido.

- No-Repudio: Se refiere al hecho que una persona o entidad no puede negar el origen, contenido ni recepción de una información electrónica.

- Confidencialidad: Se refiere a la capacidad de mantener una información electrónica protegida y accesible para su divulgación o revelación sólo a una lista determinada de personas autorizadas y responsables.

- Accesibilidad: Se refiere al hecho que los datos e información electrónica siempre estén disponibles y accesibles para las operaciones estratégicas de la entidad y para la gestión de los negocios.

Los criterios de confiabilidad y calidad de la evidencia electrónica de auditoría se relacionan con los nueve elementos que, según cicA, presentan diferencias entre la evidencia de auditoría tradicional y el soporte electrónico. Esto implica que en la revisión y evaluación de información electrónica deben cumplirse los referidos criterios, con la finalidad de asegurar el desarrollo del trabajo en forma competente por parte del auditor (CICA, 2003). 
Competencias de los auditores gubernamentales chilenos para la obtención de evidencia electrónica...

Tabla 2

Atributos e-evidencia versus criterios de confiabilidad de la información (CICA, 2003)

\begin{tabular}{|c|c|c|}
\hline Atributo & $\begin{array}{c}\text { Criterios de } \\
\text { confiabilidad y calidad }\end{array}$ & Relaciones elemento - criterios \\
\hline Origen & $\begin{array}{l}\text { Autenticación de } \\
\text { Origen, No repudio }\end{array}$ & $\begin{array}{l}\text { Para determinar el origen es necesario establecer que se trata de un } \\
\text { documento cuya fuente es auténtica (confirma la identidad de una } \\
\text { organización o persona) y que no puede negarse (no puede desconocer } \\
\text { que lo envió o recibió). }\end{array}$ \\
\hline Alteración & Integridad & $\begin{array}{l}\text { Para determinar que el mensaje de datos no ha tenido una alteración no } \\
\text { autorizada debe establecerse que el documento es integro al ser generado, } \\
\text { procesado, transmitido, (recibido y enviado) mantenido y/o archivado. }\end{array}$ \\
\hline Aprobación & Autorización & $\begin{array}{l}\text { Para determinar que la información ha sido debidamente aprobada debe } \\
\text { establecerse que ha sido autorizada cuando fue creada, procesada, } \\
\text { grabada, corregida, enviada, archivada, accesada y destruida sólo por } \\
\text { personas autorizadas y responsables. }\end{array}$ \\
\hline Completitud & Integridad, Accesibilidad & $\begin{array}{l}\text { Para determinar que la información es completa debe determinarse } \\
\text { que no falten datos, que estén completos, que no estén enmendados } \\
\text { (integridad) y que estén accesibles y disponibles para las operaciones } \\
\text { estratégicas de la entidad y para la gestión de los negocios. }\end{array}$ \\
\hline Lectura & Accesibilidad & $\begin{array}{l}\text { Para determinar que la información se pueda leer debe establecerse } \\
\text { la visualización, accesibilidad y disponibilidad a los datos en cualquier } \\
\text { momento que se requiera. }\end{array}$ \\
\hline Formato & Integridad, Accesibilidad & $\begin{array}{l}\text { Para determinar el formato se debe establecer que los datos no han } \\
\text { sido modificados ni alterados indebidamente y se debe disponer de } \\
\text { accesibilidad y disponibilidad a los datos en el momento que se requiera. }\end{array}$ \\
\hline $\begin{array}{c}\text { Almacenamiento o } \\
\text { Archivo }\end{array}$ & $\begin{array}{l}\text { Accesibilidad, } \\
\text { Autorización }\end{array}$ & $\begin{array}{l}\text { Para determinar el archivo seguro de la información se debe establecer } \\
\text { un adecuado acceso al repositorio con características especiales de } \\
\text { seguridad, integridad y disponibilidad, definidas por la Ley, sólo por } \\
\text { personas autorizadas que pueden registrar o almacenar información. }\end{array}$ \\
\hline $\begin{array}{l}\text { Disponibilidad y } \\
\text { Accesibilidad }\end{array}$ & Accesibilidad & $\begin{array}{l}\text { Para determinar adecuada disponibilidad de la información se debe } \\
\text { establecer acceso oportuno a los registros de acuerdo a los tiempos de } \\
\text { la auditoría. }\end{array}$ \\
\hline Firma & $\begin{array}{l}\text { Autenticación, } \\
\text { Autorización, } \\
\text { Integridad, No repudio, } \\
\text { Confidencialidad }\end{array}$ & $\begin{array}{l}\text { La documentación debidamente firmada establece que la persona que } \\
\text { envió o recibió el documento no puede negarlo o repudiarlo, que si la } \\
\text { persona tiene autorización para una operación, con la firma lo prueba, } \\
\text { que se trata de un documento cuyo origen es auténtico, que los datos } \\
\text { son íntegros y que, incluso, contribuye en forma adicional a mantener } \\
\text { la confidencialidad de los datos mediante la aplicación de técnicas de } \\
\text { cifrado y su uso como clave segura. }\end{array}$ \\
\hline
\end{tabular}

\subsection{Principales normas técnicas que regulan la evidencia en auditoría}

Existen varias normas técnicas que, a nivel internacional, regulan la evidencia en auditoría. Entre ellas podemos citar la Guía Internacional de Auditoría núm. 8, emitida por The International Federation of Accountants (IFAC); las Guías de Auditoría SISAS núm. 3, de Information Systems Audit and Control Association (ISACA); la Norma de Auditoría núm. 39 sección 150 y 326, y la núm. 54 del Colegio de Contadores de Chile A. G. Así como la Declaración sobre Normas de Auditoría-SAS núm. 31 modificada por la SAS núm. 80, emitida por The American Institute of Certified Public Accountants (AICPAC). 
En el caso de Chile, como en el de otros países, el mundo informático ha modificado las concepciones tradicionales del Derecho, en el cual se requería la presencia física de las partes para la firma de un contrato o de un documento en papel para acreditar la existencia de una obligación. Como parte del reconocimiento de este cambio en el año 2001 se publica y promulga la Ley núm. 19,799 sobre Documento y Firma Electrónica. Con la dictación de dicha Ley surge un mandato para la Administración del Estado que se traduce en su uso progresivo y la necesidad de reemplazar el soporte en papel por el soporte electrónico, lo que se ve reforzado por las políticas de Gobierno Electrónico que se han impulsado.

Además se han dictado, por el Ministerio Secretaría General de la Presidencia, tres normas técnicas que son obligatorias para el Sector Público. La primera está relacionada con la eficiencia de las comunicaciones electrónicas entre órganos de la Administración del Estado y entre estos y los ciudadanos (Decreto Supremo núm. 77 de MINSEGPRES de 23 de diciembre de 2004). La segunda norma regula la interoperabilidad de documentos electrónicos y establece el estándar de los documentos electrónicos a utilizar en la Administración del Estado, es decir, el Extensible Markup Language-XML. (Decreto Supremo núm. 81 MINSEGPRES del 23 de mayo de 2004.) Y la tercera norma los requisitos de seguridad y confidencialidad que deben cumplir los documentos electrónicos de los órganos de la Administración del Estado (Decreto Supremo núm. 83 de MINSEGPRES del 8 de febrero de 2005).

\section{Diseño de investigación}

El diseño de investigación se llevó a cabo en cuatro fases. La primera correspondió a identificar los principales elementos que distinguen la evidencia electrónica sobre aquella en papel. En la segunda fase se utilizaron las características de la evidencia electrónica para construir un modelo de competencias, tanto conceptuales como procedimentales para obtener evidencia de auditoría confiable y de calidad. Dado el modelo de competencias, en la tercera fase, se procedió a construir una encuesta que permitió determinar las competencias de los auditores gubernamentales que participaron de este estudio. Por último, la cuarta fase se procedió a analizar los datos recolectados.

\subsection{Modelo de competencias}

La presente investigación se ha orientado a estudiar las competencias específicas de los auditores internos de la población definida para obtener, en términos razonables, evidencia electrónica confiable y de calidad. Para ello se utilizó un modelo de competencias denominado "Planeación por Competencias" (Román, 2004), que contiene 
la definición de una competencia genérica, competencias conceptuales, procedimentales y actitudinales, así como descriptores que verifican la presencia y la calidad de esas competencias. Este modelo se usó para determinar, mediante una investigación por encuesta, si los auditores contaban con el conocimiento y las competencias genéricas y las específicas definidas en él.

Con base en los elementos que distinguen a la evidencia electrónica sobre aquélla en papel, se estableció un modelo de las competencias tanto conceptuales como procedimentales requeridas por un auditor para obtener evidencia de auditoría confiable y de calidad.

Tabla 3

Competencias requeridas para obtener evidencia electrónica de auditoría

\begin{tabular}{|c|c|c|c|}
\hline Descriptores & Competencias conceptuales & Competencias procedimentales & $\begin{array}{l}\text { Competencias } \\
\text { actitudinales }\end{array}$ \\
\hline $\begin{array}{l}\text { Familiaridad en el } \\
\text { trabajo con documentos } \\
\text { electrónicos. }\end{array}$ & $\begin{array}{l}\text { Conocimiento y uso de los } \\
\text { tipos de documentos tributarios } \\
\text { electrónicos y de la organización. }\end{array}$ & - & \multirow{10}{*}{$\begin{array}{l}\text { Debido cuidado } \\
\text { profesional. } \\
\text { Objetividad } \\
\text { Actitud crítica } \\
\text { Capacidad de análisis } \\
\text { Capacidad de } \\
\text { abstracción } \\
\text { Perseverancia } \\
\text { Escepticismo, no creer } \\
\text { sólo lo que parece } \\
\text { a primera vista en } \\
\text { pantalla. } \\
\text { Disposición y actitud } \\
\text { a aprender cosas } \\
\text { nuevas, en especial } \\
\text { tecnologías de } \\
\text { información. } \\
\text { Flexibilidad de } \\
\text { pensamiento. } \\
\text { Actitud favorable } \\
\text { hacia la actualización } \\
\text { permanente. }\end{array}$} \\
\hline $\begin{array}{l}\text { Dificultad en el trabajo } \\
\text { con documentos } \\
\text { electrónicos. }\end{array}$ & $\begin{array}{l}\text { Grado de conocimiento de } \\
\text { dificultades en el trabajo con } \\
\text { documento electrónico. }\end{array}$ & - & \\
\hline $\begin{array}{l}\text { Identificar medios de } \\
\text { soporte de documentos } \\
\text { electrónicos. }\end{array}$ & $\begin{array}{l}\text { Conocimiento de los medios } \\
\text { de soporte de un documento } \\
\text { electrónico. }\end{array}$ & - & \\
\hline $\begin{array}{l}\text { Identificar tipos de } \\
\text { formatos de documentos } \\
\text { electrónicos. }\end{array}$ & $\begin{array}{l}\text { Conocimientos sobre formatos de } \\
\text { documentos electrónicos: texto, } \\
\text { presentación, video, imágenes, } \\
\text { entre otros. }\end{array}$ & - & \\
\hline $\begin{array}{l}\text { Determinar origen del } \\
\text { documento electrónico } \\
\text { recibido. }\end{array}$ & \multirow{6}{*}{$\begin{array}{l}\text { Conocimientos de los elementos } \\
\text { que distinguen la evidencia } \\
\text { electrónica de auditoría } \\
\text { (Autenticación, Autorización, } \\
\text { Integridad, No-Repudio, } \\
\text { Confidencialidad, Accesibilidad). }\end{array}$} & $\begin{array}{l}\text { Examinar, verificar y determinar el } \\
\text { origen, emisor o creador del documento } \\
\text { electrónico. }\end{array}$ & \\
\hline $\begin{array}{l}\text { Determinar integridad del } \\
\text { documento electrónico. }\end{array}$ & & $\begin{array}{l}\text { Evaluar y determinar la completitud, } \\
\text { alteración o modificación en el contenido } \\
\text { del documento electrónico. }\end{array}$ & \\
\hline $\begin{array}{l}\text { Relacionar aprobación en } \\
\text { el documento electrónico } \\
\text { con funcionario que } \\
\text { cuenta con facultades. }\end{array}$ & & $\begin{array}{l}\text { Examinar y verificar la identificación del } \\
\text { funcionario que aprueba actos en el } \\
\text { documento electrónico recibido. }\end{array}$ & \\
\hline $\begin{array}{l}\text { Asegurar visualización } \\
\text { fiel del contenido de } \\
\text { documento electrónico. }\end{array}$ & & $\begin{array}{l}\text { Examinar y determinar si la } \\
\text { representación en el computador } \\
\text { corresponde fiel e íntegramente al } \\
\text { contenido del documento electrónico. }\end{array}$ & \\
\hline $\begin{array}{l}\text { Obtener accesibilidad } \\
\text { adecuada y segura } \\
\text { al contenido del } \\
\text { documento electrónico. }\end{array}$ & & $\begin{array}{l}\text { Acceso seguro a los repositorios } \\
\text { formales y posteriormente, al contenido } \\
\text { del documento electrónico. }\end{array}$ & \\
\hline $\begin{array}{l}\text { Reconocer Firma } \\
\text { Electrónica Simple en } \\
\text { documento electrónico. }\end{array}$ & & $\begin{array}{l}\text { Examinar y distinguir si un documento } \\
\text { electrónico cuenta con Firma Electrónica } \\
\text { Simple formal y válida. }\end{array}$ & \\
\hline
\end{tabular}


Daniella Caldana, Ricardo Correa y Héctor Ponce

\subsection{Encuesta}

La recolección de datos se desarrolló a través de una encuesta en la que se incorporaron los descriptores o identificadores de acciones que explican una conducta efectiva subordinada a las competencias específicas para obtener evidencia electrónica de auditoría competente. Estos descriptores muestran la relación entre los nueve elementos que se ven afectados por el cambio, desde la evidencia tradicional a la electrónica, y los seis criterios que aseguran la confiabilidad y calidad de evidencia electrónica de auditoría.

Dicha encuesta incorpora 10 preguntas y 48 ítems asociados a las competencias conceptuales y procedimentales para los 11 descriptores definidos en el modelo (no se consideró las competencias actitudinales). La encuesta consideró, para cada una de las 10 preguntas, 4 ó 5 respuestas que incluían 1 ó 2 respuestas correctas y 2 ó 3 respuestas incorrectas respecto de las competencias conceptuales o procedimentales definidas en el modelo. Se exceptúan aquéllas donde sólo se quería medir conocimiento. En cada una de las 10 preguntas se agregó la opción “otros” como respuesta con la finalidad que los individuos pudieran aclarar su respuesta.

Para obtener y analizar las respuestas de la población en la encuesta se usó una escala tipo Likert ordinal, estructurada de acuerdo a las siguientes cinco categorías; Nunca, Rara vez, Ocasionalmente, Generalmente y Siempre. Posteriormente, en el desarrollo de la investigación, para obtener un mejor análisis, se reagruparon las cinco categorías ya definidas en tres nuevas categorías; Nunca o Rara vez, Ocasionalmente y Generalmente o Siempre. La categoría Ocasionalmente se consideró como una respuesta neutra.

A continuación, se presenta como ejemplo, las preguntas 4 y 5 de la encuesta, indicando las competencias que se evalúan y su relación con los atributos de la evidencia electrónica y los criterios de información asociados. Se detalla además si las afirmaciones que componen las respuestas a la pregunta son correctas o incorrectas. 
Competencias de los auditores gubernamentales chilenos para la obtención de evidencia electrónica...

Tabla 4

Ejemplos de relación entre encuesta, competencias evaluadas, atributos e-evidencia y criterio de información asociado

\begin{tabular}{|c|c|c|c|c|c|}
\hline \multicolumn{6}{|c|}{ Pregunta núm. 4: ¿De qué forma determina cuál es el origen (emisor o creador) de un documento electrónico? } \\
\hline Núm. & Respuesta & $\begin{array}{l}\text { Competencia } \\
\text { específica que evalúa }\end{array}$ & $\begin{array}{l}\text { Atributos } \\
\text { e-evidencia }\end{array}$ & $\begin{array}{l}\text { Criterio } \\
\text { información } \\
\text { asociado }\end{array}$ & $\begin{array}{l}\text { Valoración de } \\
\text { respuesta }\end{array}$ \\
\hline P.4.1 & $\begin{array}{l}\text { Asocia el origen directamente con la } \\
\text { persona que se lo entregó o se lo envió } \\
\text { vía e-mail. }\end{array}$ & \multirow{4}{*}{$\begin{array}{l}\text { Examinar, verificar y } \\
\text { determinar el origen, } \\
\text { emisor o creador del } \\
\text { documento electrónico. }\end{array}$} & \multirow{4}{*}{$\begin{array}{l}\text { Origen o } \\
\text { Fuente }\end{array}$} & \multirow{4}{*}{$\begin{array}{l}\text { Autenticación } \\
\text { de origen }\end{array}$} & Correcto \\
\hline P.4.2 & $\begin{array}{l}\text { Abre el documento y visualiza en pantalla } \\
\text { del PC el contenido del mismo, buscando } \\
\text { en el contenido documento, datos y } \\
\text { antecedentes de quien lo creó. }\end{array}$ & & & & Erróneo \\
\hline P.4.3 & $\begin{array}{l}\text { Lo abre y después de leerlo envía una carta } \\
\text { de confirmación al presunto emisor. }\end{array}$ & & & & Erróneo \\
\hline P.4.4 & $\begin{array}{l}\text { Busca en la estructura digital del } \\
\text { documento, información técnica sobre su } \\
\text { origen. }\end{array}$ & & & & Correcto \\
\hline \multicolumn{6}{|c|}{$\begin{array}{l}\text { Pregunta núm. 5: ¿Qué cosa haría o se fijaría en un documento electrónico para asegurarse que no ha sido } \\
\text { modificado o alterado en forma intencionada o por error? }\end{array}$} \\
\hline Núm. & Respuesta & $\begin{array}{l}\text { Competencia } \\
\text { específica que evalúa }\end{array}$ & $\begin{array}{l}\text { Atributos } \\
\text { e-evidencia }\end{array}$ & $\begin{array}{l}\text { Criterio } \\
\text { información } \\
\text { asociado }\end{array}$ & $\begin{array}{l}\text { Valoración de } \\
\text { respuesta }\end{array}$ \\
\hline P.5.1 & $\begin{array}{l}\text { Abre el documento en pantalla y lo } \\
\text { imprime, con la finalidad de verificar los } \\
\text { datos contenidos en el documento impreso } \\
\text { en papel. }\end{array}$ & \multirow{4}{*}{$\begin{array}{l}\text { Evaluar y determinar la } \\
\text { completitud, alteración } \\
\text { o modificación en } \\
\text { el contenido del } \\
\text { documento electrónico. }\end{array}$} & \multirow{4}{*}{ Alteración } & \multirow{4}{*}{ Integridad } & Erróneo \\
\hline P.5.2 & $\begin{array}{l}\text { Se asegura que el documento no está } \\
\text { alterado y completo en su contenido, si } \\
\text { viene con una password para leerlo que } \\
\text { sólo usted y el emisor conocen. }\end{array}$ & & & & Correcto \\
\hline P.5.3 & $\begin{array}{l}\text { Se asegura que el documento no está } \\
\text { alterado y completo en su contenido, si } \\
\text { viene firmado electrónicamente por el } \\
\text { emisor (según procedimiento aprobado por } \\
\text { la organización). }\end{array}$ & & & & Correcto \\
\hline P.5.4 & $\begin{array}{l}\text { Lo imprime y con base al documento } \\
\text { impreso en papel hace verificaciones, } \\
\text { cuadraturas de saldos, verificación de } \\
\text { fechas, etcétera. }\end{array}$ & & & & Erróneo \\
\hline
\end{tabular}

\subsection{Población y Muestra}

Para los efectos de esta investigación se consideró a los auditores que trabajan para aquellos ministerios y servicios de la Administración Pública del Estado (excluyendo Municipalidades y Empresas del Estado) que se encuentran acogidos al Sistema de Auditoría del Programa de Mejoramiento de la Gestión (PMG) del año 2005 (DIPRES, 2005). 
El Programa de Mejoramiento de la Gestión es un programa al cual se acogen libremente los servicios públicos y que conlleva para ellos la obligación de cumplir determinadas metas clasificadas por etapas en diversas áreas, una de las cuales es auditoría interna. En el año 2005, existían 110 unidades de auditoría interna acogidas al Programa de Mejoramiento de la Gestión, con casi 400 auditores distribuidos en 18 ministerios.

Por lo tanto, se estableció como población objetivo a los auditores de servicios públicos que cuentan con un Programa Mejoramiento de la Gestión y con un Sistema de Auditoría Interna. Luego, se seleccionó a aquellos auditores que trabajan para los servicios públicos pertenecientes a 9 ministerios de la Administración del Estado y que representan las áreas productiva, de fomento, social, inversiones, desarrollo regional y estratégica del Estado. Como resultado, el tamaño de la población a encuestar correspondió a 237 profesionales que se desempeñan en labores de auditoría interna en los servicios públicos seleccionados.

Un total de 197 personas respondió la encuesta, correspondiente a un 83.1\% de la población, lo que significó trabajar con un error del 3\% y un nivel de confianza del 95\%.

\subsection{Confiabilidad encuesta}

El análisis de confiabilidad del instrumento arroja que para 36 ítems (preguntas número 3 a la 10 relacionadas con competencias conceptuales y procedimentales), y considerando a los 197 individuos encuestados, se obtiene un coeficiente de confiabilidad Alpha de Cronbach de 0.9283.

\section{Análisis de los datos}

En esta sección se presenta un análisis de los datos obtenidos, en primer lugar, a través de informes entregados al Consejo de Auditoría Interna de Gobierno y, en segundo lugar, un detallado análisis de los datos obtenidos a través de la encuesta.

\subsection{Características de la población}

Durante el desarrollo de la investigación se realizaron análisis de una serie de datos genéricos (no identificables con personas ni instituciones) que los auditores que componen la población han presentado al Consejo de Auditoría Interna General de Gobierno en el marco del Sistema de Auditoría del Programa de Mejoramiento de la Gestión-PMG. Estos análisis guardan relación con aspectos como la distribución de los 
auditores de la población, sus profesiones y disciplinas, su especialización (cursos, diplomados, magíster), necesidades de capacitación declaradas, participación en los sistemas de información, contenido de materias del área informática en los planes de auditoría presentados por los servicios y experiencia en auditoría interna. A continuación se presentan detalles respecto a la distribución por ministerio, las principales profesiones y los años de experiencia en auditoría.

Tabla 5

Auditores por ministerio

Gráfico 1: Porcentaje de auditores por ministerio

\begin{tabular}{|c|c|c|}
\hline Ministerio & $\begin{array}{c}\text { Número de } \\
\text { auditores }\end{array}$ & (\%) \\
\hline A & 43 & $18.1 \%$ \\
\hline B & 42 & $17.7 \%$ \\
\hline C & 35 & $14.8 \%$ \\
\hline D & 29 & $12.2 \%$ \\
\hline E & 24 & $10.1 \%$ \\
\hline F & 23 & $9.7 \%$ \\
\hline G & 22 & $9.3 \%$ \\
\hline H & 14 & $5.9 \%$ \\
\hline I & 5 & $2.1 \%$ \\
\hline Total & $\mathbf{2 3 7}$ & $\mathbf{1 0 0 . 0 \%}$ \\
\hline
\end{tabular}

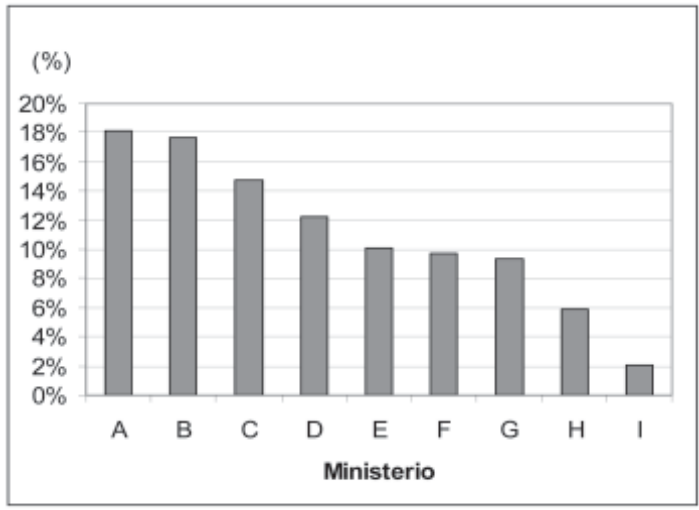

Se observa en el gráfico 1 que la distribución de auditores gubernamentales es relativamente uniforme, con mayor concentración en cuatro de ellos (62.8\%).

Gráfico 2: \% auditores por profesión

\begin{tabular}{|c|c|c|}
\hline Profesión & $\begin{array}{c}\text { Número de } \\
\text { auditores }\end{array}$ & (\%) \\
\hline Contador Auditor & 133 & $56.1 \%$ \\
\hline $\begin{array}{c}\text { Ingeniero } \\
\text { Comercial }\end{array}$ & 26 & $11.0 \%$ \\
\hline Adm. Público & 15 & $6.3 \%$ \\
\hline Ingeniero Civil & 12 & $5.1 \%$ \\
\hline Abogado & 10 & $4.2 \%$ \\
\hline Otros & 41 & $17.3 \%$ \\
\hline Total & $\mathbf{2 3 7}$ & $\mathbf{1 0 0 . 0 \%}$ \\
\hline
\end{tabular}

Tabla 6: Profesión de los auditores

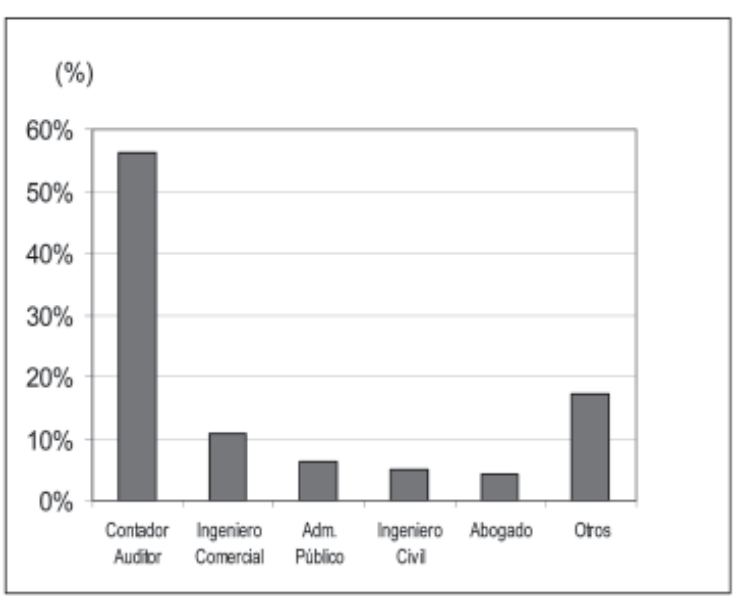


Se observa en el gráfico 2 que principalmente los individuos de la población en estudio son de profesión Contador Público y Auditor, con un 56.1\% y, en menor porcentaje, de profesión Ingeniero Comercial, con un $11 \%$; por lo que las disciplinas que predominan son la Contabilidad, Auditoría y Administración.

\begin{tabular}{|c|c|c|}
\hline $\begin{array}{c}\text { Años de } \\
\text { Experiencia }\end{array}$ & $\begin{array}{c}\text { Número de } \\
\text { auditores }\end{array}$ & (\%) \\
\hline $1-5$ años & 127 & $53.6 \%$ \\
\hline $5-10$ años & 65 & $27.4 \%$ \\
\hline Más de 10 años & 45 & $19.0 \%$ \\
\hline Total & 237 & $100.0 \%$ \\
\hline
\end{tabular}

Tabla 7: Años experiencia auditores

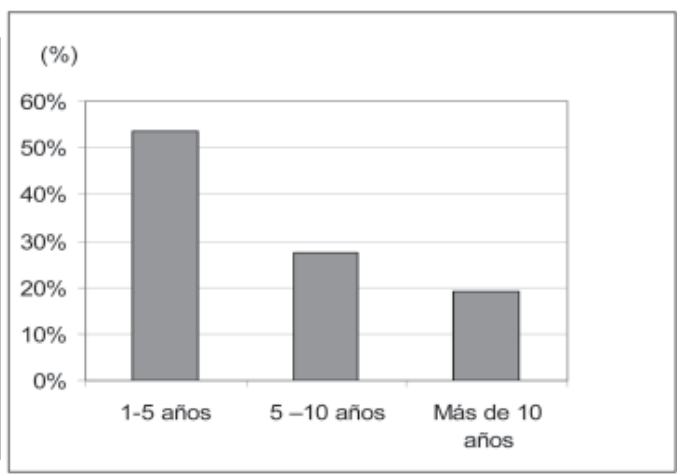

Gráfico 3: Años experiencia auditores

La experiencia laboral de los auditores está concentrada mayoritariamente en el rango de 1 a 5 años y, aunque no se cuenta con información respecto a la edad de estos profesionales, dado los años de experiencia, se estima que se trata de profesionales relativamente jóvenes.

\subsection{Análisis de los datos de la encuesta}

A continuación se presenta el análisis descriptivo del resultado obtenido en cada una de las preguntas contenidas en la encuesta realizada a los auditores internos de la población en estudio. No se presentan los análisis de la pregunta 3 y 7; la primera tiene relación con las formas de envío o recepción del documento electrónico y, la segunda, con el formato del documento electrónico. Ambas preguntas se relacionan con conocimientos más que con procedimientos específicos respecto a este tipo de evidencia, por lo que el análisis que se presenta a continuación no se ve afectado.

\subsubsection{Familiaridad en el trabajo con documentos electrónicos}

Mediante la pregunta ¿Qué tipo de documentos electrónicos le ha tocado revisar, utilizar o emitir? se evaluó el conocimiento y utilización sobre algunos tipos de Documentos Tributarios Electrónicos (DTE), así como otros de uso corriente en los servicios públicos. 
Competencias de los auditores gubernamentales chilenos para la obtención de evidencia electrónica...

Tabla 8

Documentos electrónicos que revisa, utiliza o emite

\begin{tabular}{|c|l|c|c|c|}
\hline Núm. & \multicolumn{1}{|c|}{ Respuesta } & $\begin{array}{c}\text { Nunca o } \\
\text { Rara vez }\end{array}$ & Ocasionalmente & $\begin{array}{c}\text { Generalmente o } \\
\text { Siempre }\end{array}$ \\
\hline P.1.1 & Facturas electrónicas & $76.1 \%$ & $19.8 \%$ & $4.1 \%$ \\
\hline P.1.2 & Boletas de honorarios electrónica & $60.4 \%$ & $21.3 \%$ & $18.3 \%$ \\
\hline P.1.3 & Contratos electrónicos & $78.7 \%$ & $13.2 \%$ & $8.1 \%$ \\
\hline P.1.4 & Certificados emitidos por organismos públicos & $61.4 \%$ & $22.8 \%$ & $15.7 \%$ \\
\hline P.1.5 & Resoluciones electrónicas emitidas en el Servicio & $71.6 \%$ & $15.7 \%$ & $12.7 \%$ \\
\hline P.1.6 & Memorandos u oficios electrónicos & $39.1 \%$ & $27.9 \%$ & $33.0 \%$ \\
\hline P.1.7 & Libros, revistas electrónicas & $60.9 \%$ & $19.3 \%$ & $19.8 \%$ \\
\hline \multicolumn{2}{|c|}{ Promedio de respuestas en ítems } & $\mathbf{6 4 . 0 \%}$ & $\mathbf{2 0 . 0 \%}$ & $\mathbf{1 5 . 9 \%}$ \\
\hline
\end{tabular}

En promedio, un $64.0 \%$ de los encuestados responden que nunca o rara vez han revisado, utilizado o emitido algunos de los documentos electrónicos que se incluyen en la encuesta (facturas electrónicas, boletas de honorarios electrónicas, certificados y documentos electrónicos de uso en la organización). En contraste, el 15.9\% sí ha trabajado generalmente o siempre con documentos electrónicos. Destacan las boletas de honorarios electrónicas (18.3\%) y los memorandos u oficios electrónicos (33\%). Aquéllos que ocasionalmente les ha tocado trabajar con documentos electrónicos alcanzan, en promedio, un $20 \%$, destacándose nuevamente la boleta de honorario electrónica (21.3\%) y el memorando u oficio electrónico (27.9\%).

Resulta interesante observar que uno de los documentos electrónicos más familiares para los auditores es el memorando u oficio electrónico, lo que demostraría el alto uso del correo electrónico en el sector público.

\subsubsection{Dificultad en el trabajo con documentos electrónicos}

Mediante la pregunta ¿Qué tipo de problemas ha enfrentado con los documentos electrónicos? se evaluó el grado de conocimiento de las dificultades en el trabajo con documentos electrónicos (criterios de calidad y confiabilidad asociados: autenticación de origen, autorización, accesibilidad, integridad y no repudio).

Tabla 9

Tipos de e-documentos revisados

\begin{tabular}{|c|c|c|c|c|}
\hline Núm. & Respuesta & $\begin{array}{c}\text { Nunca o Rara } \\
\text { vez }\end{array}$ & Ocasionalmente & $\begin{array}{l}\text { Generalmente } \\
\text { o Siempre }\end{array}$ \\
\hline P.2.1 & $\begin{array}{l}\text { Dificultad para obtener información acerca del documento } \\
\text { electrónico (quién lo firmó, cuándo, si fue modificado, } \\
\text { etcétera). }\end{array}$ & $68.0 \%$ & $17.3 \%$ & $14.7 \%$ \\
\hline P.2.2 & Dificultad para acceder a los registros guardados. & $68.0 \%$ & $13.2 \%$ & $18.8 \%$ \\
\hline P.2.3 & $\begin{array}{l}\text { Dificultad para verificar la exactitud y completitud del } \\
\text { documento. }\end{array}$ & $66.0 \%$ & $20.3 \%$ & $13.7 \%$ \\
\hline P.2.4 & $\begin{array}{l}\text { Dificultad para verificar la identificación del emisor y si } \\
\text { tenía las atribuciones para emitir el documento. }\end{array}$ & $61.4 \%$ & $17.3 \%$ & $21.3 \%$ \\
\hline P.2.5 & $\begin{array}{l}\text { Dificultad para saber si el documento que se revisó } \\
\text { correspondía exactamente al original enviado. }\end{array}$ & $62.9 \%$ & $16.2 \%$ & $20.8 \%$ \\
\hline \multicolumn{2}{|r|}{ Promedio de respuestas en ítems } & $65.3 \%$ & $16.9 \%$ & $17.9 \%$ \\
\hline
\end{tabular}


Del análisis de las respuestas, en promedio un 65.3\% de los auditores encuestados no presentan mayor dificultad para trabajar con documentos electrónicos, en contraste con el $17.9 \%$ en promedio que dice que generalmente o siempre presenta dificultades de algún tipo al trabajar con documentos electrónicos. Es probable que el alto número de auditores que no presenta dificultades con el e-documento tenga su origen en la falta de conocimiento y experiencia en la utilización y revisión de documentos electrónicos pues, como se observa en el análisis de la pregunta 1 y como se demuestra en la tabla 16, sólo un $8.1 \%$ de la población presenta habilidades para trabajar con evidencia electrónica de auditoría.

\subsubsection{Determinación del origen del documento electrónico recibido}

Mediante la pregunta ¿De qué forma determina cuál es el origen (emisor o creador) de un documento electrónico? se evaluó la capacidad de examinar, verificar y determinar el origen, emisor o creador del documento electrónico (criterio de calidad y confiabilidad asociado: autenticación de origen).

Tabla 10

Origen e-documento

\begin{tabular}{|l|l|c|c|c|}
\hline Núm & \multicolumn{1}{|c|}{ Respuesta } & $\begin{array}{c}\text { Nunca o } \\
\text { Rara vez }\end{array}$ & Ocasionalmente & $\begin{array}{c}\text { Generalmente } \\
\text { o Siempre }\end{array}$ \\
\hline P.4.1 & $\begin{array}{l}\text { Asocia el origen directamente con la persona que se lo entregó o } \\
\text { se lo envió vía e-mail (correcto). }\end{array}$ & $29.4 \%$ & $12.2 \%$ & $58.4 \%$ \\
\hline P.4.2 & $\begin{array}{l}\text { Abre el documento y visualiza en pantalla del PC el contenido } \\
\text { del mismo, buscando en el contenido documento, datos y } \\
\text { antecedentes de quien lo creó (erróneo) }\end{array}$ & $35.5 \%$ & $15.2 \%$ & $49.2 \%$ \\
\hline P.4.3 & $\begin{array}{l}\text { Lo abre y, después de leerlo, envía una carta de confirmación al } \\
\text { presunto emisor (erróneo). }\end{array}$ & $58.9 \%$ & $19.3 \%$ & $21.8 \%$ \\
\hline P.4.4 & $\begin{array}{l}\text { Busca en la estructura digital del documento información técnica } \\
\text { sobre su origen (correcto). }\end{array}$ & $50.3 \%$ & $17.8 \%$ & $32.0 \%$ \\
\hline Promedio respuestas en ítems correctos & $39.9 \%$ & $15.0 \%$ & $45.2 \%$ \\
\hline Promedio respuestas en ítems erróneos & $\mathbf{4 7 . 2 0 \%}$ & $\mathbf{1 7 . 2 5 \%}$ & $35.50 \%$ \\
\hline
\end{tabular}

En la Tabla 10 se observa que en promedio un $47.2 \%$ de los auditores muestra falencias a la hora de autentificar el origen de un documento electrónico; mientras que un 45.2\% muestra competencias en esta materia. Sólo un 32\% de los auditores busca en la estructura del documento electrónico información sobre su origen.

\subsubsection{Determinación de la integridad del documento electrónico}

Mediante la pregunta ¿Qué cosa haría o se fijaría en un documento electrónico, para asegurarse que no ha sido modificado o alterado en forma intencionada 0 por error? se evaluó la capacidad de examinar y determinar la completitud, alteración o modificación en el contenido del documento electrónico (criterio de calidad y confiabilidad asociado: integridad). 
Competencias de los auditores gubernamentales chilenos para la obtención de evidencia electrónica...

Tabla 11

Alteración e-documento

\begin{tabular}{|c|l|c|c|c|}
\hline Núm. & \multicolumn{1}{|c|}{ Respuesta } & $\begin{array}{c}\text { Nunca o } \\
\text { Rara vez }\end{array}$ & $\begin{array}{c}\text { Ocasio- } \\
\text { nalmente }\end{array}$ & $\begin{array}{c}\text { Generalmente o } \\
\text { Siempre }\end{array}$ \\
\hline P.5.1 & $\begin{array}{l}\text { Abre el documento en pantalla y lo imprime, con la finalidad } \\
\text { de verificar los datos contenidos en el documento impreso en } \\
\text { papel (erróneo). }\end{array}$ & $34.5 \%$ & $15.2 \%$ & $50.3 \%$ \\
\hline P.5.2 & $\begin{array}{l}\text { Se asegura que el documento no está alterado y completo en } \\
\text { su contenido, si viene con una password para leerlo que sólo } \\
\text { usted y el emisor conocen (correcto). }\end{array}$ & $52.3 \%$ & $9.6 \%$ & $38.1 \%$ \\
\hline P.5.3 & $\begin{array}{l}\text { Se asegura que el documento no está alterado y completo } \\
\text { en su contenido, si viene firmado electrónicamente por el } \\
\text { emisor. Según procedimiento aprobado por la organización } \\
\text { (correcto). }\end{array}$ & $45.2 \%$ & $11.7 \%$ & $43.1 \%$ \\
\hline P.5.4 & $\begin{array}{l}\text { Lo imprime y con base al documento impreso en papel hace } \\
\text { verificaciones, cuadraturas de saldos, verificación de fechas, } \\
\text { etc. (erróneo). }\end{array}$ & $39.6 \%$ & $15.7 \%$ & $44.7 \%$ \\
\hline \multicolumn{2}{|l|}{} & $48.8 \%$ & $10.7 \%$ & $40.6 \%$ \\
\hline Promedio respuestas en ítems correctos & $37.05 \%$ & $15.45 \%$ & $47.50 \%$ \\
\hline
\end{tabular}

Destacan de las respuestas erróneas la inclinación por la necesidad de imprimir los documentos electrónicos para realizar el análisis de integridad (47.5\%). Sobresalen también aquellos auditores que indican que nunca o rara vez utilizan una password privada para verificar integridad del documento (52.3\%). La mayoría (45.2\%) tampoco parece reconocer la relevancia de la firma electrónica. Por consiguiente, se puede concluir que existe una clara tendencia que refleja déficit de conocimiento sobre el concepto de documento electrónico y falta de competencias específicas para determinar la integridad del contenido de un documento electrónico.

\subsubsection{Relacionar aprobación en el documento electrónico con funcionario que cuenta con facultades}

Mediante la pregunta ¿Cómo identifica que un documento electrónico está debidamente aprobado por el funcionario que cuenta con tal facultad en el Servicio? se evaluó la capacidad de examinar y verificar la identificación del funcionario que aprueba actos en el documento electrónico recibido (criterios de calidad y confiabilidad asociados: autorización y autenticación de origen). 
Tabla 12

Aprobación e-documento

\begin{tabular}{|c|c|c|c|c|}
\hline Núm. & Respuesta & $\begin{array}{l}\text { Nunca o } \\
\text { Rara vez }\end{array}$ & $\begin{array}{l}\text { Ocasio- } \\
\text { nalmente }\end{array}$ & $\begin{array}{l}\text { Generalmente o } \\
\text { Siempre }\end{array}$ \\
\hline P.6.1 & $\begin{array}{l}\text { Abre el documento y lo imprime, con la finalidad de examinar y } \\
\text { determinar si viene con el nombre de la persona con atribuciones } \\
\text { para firmar, cargo y facsímil de firma en su contenido (erróneo). }\end{array}$ & $51.3 \%$ & $16.8 \%$ & $32.0 \%$ \\
\hline P.6.2 & $\begin{array}{l}\text { Abre el documento y en pantalla examina que tiene nombre de } \\
\text { la persona con atribuciones para firmar, cargo y facsímil de firma } \\
\text { en su contenido (erróneo). }\end{array}$ & $41.6 \%$ & $11.2 \%$ & $47.2 \%$ \\
\hline P.6.3 & $\begin{array}{l}\text { Se asegura que el documento está debidamente aprobado } \\
\text { porque se lo remitió vía e-mail una persona que tiene las } \\
\text { facultades para aprobar (correcto). }\end{array}$ & $43.1 \%$ & $11.7 \%$ & $45.2 \%$ \\
\hline P.6.4 & $\begin{array}{l}\text { Se comunica con la persona o funcionario facultado para aprobar } \\
\text { y le consulta acerca del nivel de aprobación del documento } \\
\text { remitido (erróneo). }\end{array}$ & $55.3 \%$ & $19.3 \%$ & $25.4 \%$ \\
\hline P.6.5 & $\begin{array}{l}\text { Se asegura que el documento está aprobado en su contenido si } \\
\text { viene firmado electrónicamente por emisor. Según procedimiento } \\
\text { aprobado por la organización (correcto). }\end{array}$ & $50.8 \%$ & $11.2 \%$ & $38.1 \%$ \\
\hline \multicolumn{2}{|c|}{ Promedio respuestas en ítems correctos. } & $47.0 \%$ & $11.5 \%$ & $41.7 \%$ \\
\hline \multicolumn{2}{|c|}{ Promedio respuestas en ítems erróneos. } & $49.4 \%$ & $15.8 \%$ & $34.9 \%$ \\
\hline
\end{tabular}

De las respuestas erróneas, destaca aquélla referida a que bastaría sólo con el examen del contenido visualizado en pantalla del computador para verificar que un documento ha sido debidamente firmado (47.2\%). Adicionalmente, destaca la falta de capacidades para determinar la aprobación del contenido al venir firmado electrónicamente por su emisor (50.8\%).

\subsubsection{Asegurar visualización fiel en relación al contenido del documento electrónico}

Mediante la pregunta ¿Cómo se asegura que lo que visualiza en pantalla corresponde exactamente al contenido del documento electrónico correspondiente? se evaluó la capacidad de examinar y determinar si la representación en el computador corresponde fiel e íntegramente al contenido del documento electrónico (criterios de calidad y confiabilidad asociados: accesibilidad e integridad).

Tabla 13

Visualización e-documento

\begin{tabular}{|c|l|c|c|c|}
\hline Núm. & \multicolumn{1}{|c|}{ Respuesta } & $\begin{array}{c}\text { Nunca o } \\
\text { Rara vez }\end{array}$ & $\begin{array}{c}\text { Ocasio- } \\
\text { nalmente }\end{array}$ & $\begin{array}{c}\text { Generalmente o } \\
\text { Siempre }\end{array}$ \\
\hline P.8.1 & $\begin{array}{l}\text { Lo imprime y compara dicha impresión con lo visualizado en } \\
\text { pantalla (erróneo). }\end{array}$ & $51.8 \%$ & $16.8 \%$ & $31.5 \%$ \\
\hline P.8.2 & $\begin{array}{l}\text { Sólo le basta con visualizarlo en la pantalla del computador } \\
\text { (erróneo). }\end{array}$ & $50.3 \%$ & $10.2 \%$ & $39.6 \%$ \\
\hline P.8.3 & $\begin{array}{l}\text { Lo visualiza en pantalla y confirma de alguna manera con el } \\
\text { emisor, el contenido del documento (erróneo). }\end{array}$ & $51.3 \%$ & $24.9 \%$ & $23.4 \%$ \\
\hline P.8.4 & $\begin{array}{l}\text { Confía que la información visualizada es exacta si el software } \\
\text { o aplicación original (con licencia) que se utilizó para generar } \\
\text { el archivo, lo puede abrir sin error posteriormente (correcto). }\end{array}$ & $44.2 \%$ & $14.2 \%$ & $41.6 \%$ \\
\hline \multicolumn{2}{|l|}{ Promedio respuestas en ítems correctos } & $\mathbf{4 4 . 2 \%}$ & $\mathbf{1 4 . 2 \%}$ & $\mathbf{4 1 . 6 \%}$ \\
\hline
\end{tabular}


En la Tabla 13 se observa que en promedio un 51.1\% reconoce adecuadamente los procedimientos errados respecto a la capacidad de examinar y determinar si la representación en pantalla del documento corresponde fiel e íntegramente a su contenido.

\subsubsection{Obtener accesibilidad adecuada y segura al contenido del documento electrónico}

Mediante la pregunta ¿Cómo accede a la información contenida en los documentos electrónicos institucionales almacenados o guardados? se evaluó la capacidad de obtener acceso seguro a los repositorios formales y, posteriormente, al contenido del documento electrónico (criterios de calidad y confiabilidad asociados: accesibilidad y autorización).

Tabla 14

Acceso al e-documento

\begin{tabular}{|c|l|c|c|c|}
\hline Núm. & \multicolumn{1}{|c|}{ Respuesta } & $\begin{array}{c}\text { Nunca o } \\
\text { Rara vez }\end{array}$ & $\begin{array}{c}\text { Ocasio- } \\
\text { nalmente }\end{array}$ & $\begin{array}{c}\text { Generalmente } \\
\text { o Siempre }\end{array}$ \\
\hline P.9.1 & $\begin{array}{l}\text { Mantiene en su computador una carpeta digital con los } \\
\text { documentos electrónicos permanentemente (erróneo). }\end{array}$ & $34.5 \%$ & $12.2 \%$ & $53.3 \%$ \\
\hline P.9.2 & $\begin{array}{l}\text { Posee una cuenta y password única y segura para entrar al } \\
\text { repositorio de documentos institucionales (correcto). }\end{array}$ & $58.9 \%$ & $10.2 \%$ & $31.0 \%$ \\
\hline P.9.3 & $\begin{array}{l}\text { Cada vez que requiere imprime los documentos electrónicos y } \\
\text { los guarda en un archivador físico (erróneo). }\end{array}$ & $34.0 \%$ & $20.8 \%$ & $45.2 \%$ \\
\hline P.9.4 & $\begin{array}{l}\text { Los guarda en un medio de almacenamiento magnético u óptico } \\
\text { propio, independiente del computador, para tenerlos disponibles } \\
\text { cuando así lo requiera (erróneo). }\end{array}$ & $51.8 \%$ & $16.8 \%$ & $31.5 \%$ \\
\hline Promedio respuestas en ítems correctos & $\mathbf{5 5 . 4 \%}$ & $\mathbf{1 3 . 5 \%}$ & $\mathbf{3 1 . 3 \%}$ \\
\hline Promedio respuestas en ítems erróneos & $\mathbf{3 4 . 3 \%}$ & $\mathbf{1 6 . 5 \%}$ & $\mathbf{4 9 . 3 \%}$ \\
\hline
\end{tabular}

Destacan en las respuestas erróneas aquéllas referidas a la necesidad de contar con información en carpetas digitales para acceder a los documentos electrónicos, con un 53.3\% que lo realiza generalmente o siempre. Un 45.2\% de la población indica que imprime y guarda los documentos electrónicos impresos para su posterior uso. En general, se observa una tendencia que refleja la inexistencia de conocimientos y capacidades para determinar la accesibilidad y autorización respecto de los documentos electrónicos.

\subsubsection{Reconocer la firma electrónica simple formal en un documento electrónico}

Mediante la pregunta ¿Cómo reconoce que un documento electrónico está debidamente firmado por el emisor? se evaluó la capacidad de examinar y distinguir si un documento electrónico cuenta con Firma Electrónica Simple formal y válida (criterios de calidad y confiabilidad asociados: autenticación de origen, integridad, autorización, confidencialidad y no repudio). 
Tabla 15

Reconocimiento firma electrónica

\begin{tabular}{|c|l|c|c|c|}
\hline Núm. & \multicolumn{1}{|c|}{ Respuesta } & $\begin{array}{c}\text { Nunca o } \\
\text { Rara vez }\end{array}$ & $\begin{array}{c}\text { Ocasional- } \\
\text { mente }\end{array}$ & $\begin{array}{c}\text { Generalmente } \\
\text { o Siempre }\end{array}$ \\
\hline P.10.1 & $\begin{array}{l}\text { Abre el documento y lo imprime con la finalidad de examinar y } \\
\text { determinar si viene con el nombre de la persona con atribuciones } \\
\text { para firmar, cargo y facsímil de firma o logo de la institución en su } \\
\text { contenido (erróneo) }\end{array}$ & $49.7 \%$ & $18.8 \%$ & $31.5 \%$ \\
\hline P.10.2 & $\begin{array}{l}\text { Le basta con que el e-mail a través del cual le remiten el } \\
\text { documento provenga del correo de la persona con facultades } \\
\text { para firmar (erróneo). }\end{array}$ & $43.1 \%$ & $13.7 \%$ & $43.1 \%$ \\
\hline P.10.3 & $\begin{array}{l}\text { Abre el documento y visualiza en pantalla si contiene el nombre } \\
\text { de la persona, que tiene las facultades para firmarlo, se señala el } \\
\text { cargo, un facsímil de firma o logo de la institución (erróneo). }\end{array}$ & $43.1 \%$ & $10.7 \%$ & $46.2 \%$ \\
\hline P.10.4 & $\begin{array}{l}\text { Se asegura que el documento viene firmado electrónicamente por } \\
\text { el emisor y cuyo procedimiento para validar la firma es el que ha } \\
\text { sido aprobado formalmente en la institución (correcto). }\end{array}$ & $46.7 \%$ & $8.6 \%$ & $44.7 \%$ \\
\hline P.10.5 & $\begin{array}{l}\text { Se comunica con el supuesto firmante para que le ratifique que } \\
\text { lo firmó (erróneo). }\end{array}$ & $70.6 \%$ & $13.2 \%$ & $16.2 \%$ \\
\hline Promedio respuestas en ítems correctos & $\mathbf{4 6 . 7 \%}$ & $\mathbf{8 . 6 \%}$ & $\mathbf{1 4 . 1 \%}$ & $\mathbf{4 1 . 6 \%}$ \\
\hline Promedio respuestas en ítems erróneos & & & \\
\hline
\end{tabular}

Destacan, de las respuestas erróneas, las referidas a la búsqueda en el contenido de la visualización en pantalla de datos sobre la firma electrónica, con un $46.2 \%$ que lo realiza generalmente o siempre. Para un porcentaje importante (43.1\%), basta con un email de una persona con facultades para considerarlo una firma electrónica formal.

Se observa en general que existe una tendencia que refleja déficit de conocimiento sobre el concepto de documento electrónico y firma electrónica, así como falta de competencias específicas para determinar la autenticación de origen, integridad, autorización, confidencialidad y no repudio.

\subsubsection{Proporción Auditores con Competencias para Trabajar con e-Evidencia}

A través de un análisis de cluster intentamos dar respuesta a la siguiente pregunta: ¿Qué porcentaje de la muestra contesta en promedio generalmente o siempre a los ítems sobre competencias procedimentales identificadas correctamente, y al mismo tiempo contesta en promedio nunca o rara vez a los ítems referidos a competencias procedimentales identificadas erróneamente? La respuesta nos indicará que porcentaje de la población cuenta realmente con las competencias adecuadas para trabajar con evidencia electrónica de auditoría. En la siguiente tabla de contingencia se observa que sólo un $8.1 \%$ de la población cuenta con dichas competencias. 
Competencias de los auditores gubernamentales chilenos para la obtención de evidencia electrónica...

Tabla 16

Competencias procedimentales identificadas correctamente versus competencias procedimentales identificadas erróneamente

\begin{tabular}{|c|c|c|c|c|}
\hline \multicolumn{2}{|c|}{} & \multicolumn{2}{c|}{$\begin{array}{c}\text { Competencias procedimentales } \\
\text { erróneas }\end{array}$} & \multirow{2}{*}{ Total } \\
\cline { 3 - 5 } & $\begin{array}{c}\text { Nunca o Rara } \\
\text { vez }\end{array}$ & $\begin{array}{c}\text { Generalmente o } \\
\text { Siempre }\end{array}$ & 52.85 \\
\hline $\begin{array}{c}\text { Competencias } \\
\text { procedimentales } \\
\text { correctas }\end{array}$ & Nunca o Rara vez & $31.0 \%$ & $21.8 \%$ & $47.2 \%$ \\
\cline { 2 - 5 } & $\begin{array}{c}\text { Generalmente } \\
\text { Siempre }\end{array}$ & $\mathbf{8 . 1 \%}$ & $39.1 \%$ & $100.0 \%$ \\
\hline \multicolumn{2}{|c|}{ Total } & $39.1 \%$ & $60.9 \%$ & \\
\hline
\end{tabular}

El análisis de cluster para preguntas relacionadas con competencias procedimentales identificadas correctamente se realizó considerando 9 respuestas. Se observa la conformación de dos grupos: aquéllos que contestan en promedio nunca o rara vez en estos ítems, es decir, 104 individuos (52.8\%), y otro grupo de 93 individuos (47.2\%) que responde generalmente o siempre. Al responder nunca o rara vez en aquellas respuestas identificadas como erróneas implica que el auditor no es capaz de reconocer las competencias requeridas para trabajar con evidencia electrónica de auditoría.

El análisis cluster para las preguntas relacionadas con competencias procedimentales identificadas erróneamente se realizó considerando 17 respuestas. Se observa la conformación de dos grupos: aquéllos que en promedio contestaron nunca o rara vez a dichas respuestas, es decir, 77 individuos (39.1\%), y otro grupo de 120 individuos (60.9\%) que contestan en promedio generalmente o siempre. Al contestar generalmente o siempre en la mayoría de estas respuestas implica que el auditor no cuenta con las competencias para trabajar adecuadamente con evidencia electrónica de auditoría.

\section{Conclusiones}

Los datos recolectados a través de esta investigación demuestran que los auditores internos del sector gubernamental que participaron de este estudio, en términos generales, no demuestran conocimiento ni cuentan con las competencias necesarias para obtener evidencia electrónica de auditoría. Esto porque, por una parte, no se demuestra el "saber qué", en relación al cambio que se produce en los nueve elementos de la evidencia tradicional y de los seis criterios de aseguramiento de la confiabilidad y calidad, ni el "saber cómo", poder verificar que estos elementos y criterios se encuentran presentes en la evidencia electrónica. Específicamente destacan, por el déficit de competencias demostradas, los elementos referidos a la integridad, accesibilidad y autorización en operaciones relacionadas con el documento electrónico. La tabla siguiente resume los principales hallazgos en relación a los atributos de la evidencia electrónica de auditoría y los criterios de confiabilidad y calidad asociados. 


\begin{tabular}{|c|c|c|c|}
\hline $\begin{array}{l}\text { Atributo de } \\
\text { la Evidencia } \\
\text { Electrónica }\end{array}$ & $\begin{array}{l}\text { Criterios de } \\
\text { confiabilidad y } \\
\text { calidad }\end{array}$ & Competencias correctas & Competencias erróneas \\
\hline Origen & $\begin{array}{l}\text { Autenticación } \\
\text { de Origen, No } \\
\text { repudio }\end{array}$ & $\begin{array}{l}\mathbf{5 8 . 4 \%} \text { correctamente asocia el origen } \\
\text { con la persona que se lo entregó o se lo } \\
\text { envió vía e-mail. }\end{array}$ & $\begin{array}{l}\text { 49.2\% erróneamente abre el documento y } \\
\text { visualiza en pantalla del PC el contenido del } \\
\text { mismo, buscando en el contenido documento, } \\
\text { datos y antecedentes de quien lo creó. }\end{array}$ \\
\hline Alteración & Integridad & $\begin{array}{l}\text { 43.1\% se asegura que el documento no } \\
\text { está alterado y completo en su contenido, } \\
\text { si viene firmado electrónicamente por el } \\
\text { emisor. }\end{array}$ & $\begin{array}{l}\text { 50.3\% Abre el documento en pantalla y lo } \\
\text { imprime, con la finalidad de verificar los datos } \\
\text { contenidos en el documento impreso en papel. }\end{array}$ \\
\hline Aprobación & Autorización & $\begin{array}{l}\text { 45.2\% Se asegura que el documento } \\
\text { está debidamente aprobado porque se lo } \\
\text { remitió vía e-mail una persona que tiene } \\
\text { las facultades para aprobar. }\end{array}$ & $\begin{array}{l}\text { 47.2\% Abre el documento y en pantalla examina } \\
\text { que tiene nombre de la persona con atribuciones } \\
\text { para firmar, cargo y facsímil de firma en su } \\
\text { contenido. }\end{array}$ \\
\hline Completitud & $\begin{array}{c}\text { Integridad, } \\
\text { Accesibilidad }\end{array}$ & $\begin{array}{l}\text { 31.0\% Posee una cuenta y password } \\
\text { única y segura para entrar al repositorio } \\
\text { de documentos institucionales. }\end{array}$ & $\begin{array}{l}\text { 53.3\% Mantiene en su computador, una } \\
\text { carpeta digital con los documentos electrónicos } \\
\text { permanentemente. }\end{array}$ \\
\hline Lectura & Accesibilidad & $\begin{array}{l}\text { 41.6\% Confía que la información } \\
\text { visualizada es exacta si el software que } \\
\text { se utilizó para generar el archivo, lo } \\
\text { puede abrir sin error posteriormente. }\end{array}$ & $\begin{array}{l}39.6 \% \text { Sólo le basta con visualizarlo en la } \\
\text { pantalla del computador. }\end{array}$ \\
\hline Firma & $\begin{array}{l}\text { Autenticación, } \\
\text { Autorización, } \\
\text { Integridad, } \\
\text { No repudio, } \\
\text { Confidencialidad }\end{array}$ & $\begin{array}{l}\text { 44.7\% Se asegura de que el documento } \\
\text { viene firmado electrónicamente por el } \\
\text { emisor y cuyo procedimiento para validar } \\
\text { la firma es el que ha sido aprobado } \\
\text { formalmente en la institución. }\end{array}$ & $\begin{array}{l}\text { 46.2\% Abre el documento y visualiza en pantalla } \\
\text { si contiene el nombre de la persona, que tiene las } \\
\text { facultades para firmarlo, se señala el cargo, un } \\
\text { facsímil de firma o logo de la institución. }\end{array}$ \\
\hline
\end{tabular}

Además, un análisis de cluster demostró que sólo un $8.1 \%$ en promedio de la población cuenta con las competencias procedimentales requeridas y, a la vez, no cae en errores en la identificación de este tipo de competencias, es decir, cuenta con la competencia para obtener evidencia electrónica de auditoría confiable y de calidad. El restante $91.9 \%$ de los individuos manifiesta confusiones o ausencia de estas competencias.

La ausencia de competencias específicas para obtener evidencia electrónica de auditoría confiable y de calidad podría impactar el nivel del riesgo de auditoría, debido al incremento en los riesgos inherente de control y de detección, especialmente este último por el grado de dificultad para obtener los rastros o pistas de auditoría de las transacciones electrónicas.

Finalmente, de los resultados de este estudio, resulta preocupante que la mayoría de los auditores se acerca a los archivos y datos digitales como si ellos tuviesen las mismas cualidades intrínsecas de los documentos y datos físicos en papel. Un primer paso para ganar competencias técnicas está en apreciar estas limitaciones y comprender el impacto que está provocando en las actividades propias de auditoría el desarrollo del gobierno electrónico. 
Competencias de los auditores gubernamentales chilenos para la obtención de evidencia electrónica...

\section{Bibliografía}

Chateau J., M. Marquez y P. Gutiérrez (2003). Gobierno Electrónico en Chile: Estado del Arte. Extraído el 30 de marzo de 2005 desde: www.pryme.cl

DIPRES (2004). Medios de Verificación del Programa de Mejoramiento de la Gestión 2004. Extraído el 30 de marzo de 2005 desde: www.dipres.cl

Esmond C. y A. Lavigne (2003). Going Electronic. CA Magazine. vol. 7, núm. 135 (pp. 47-49). Extraído desde www.camagazine.com

CICA (2003). Electronic Audit Evidence, Research Report. Toronto: Canadian Institute of Chartered Accountants.

For d, W. y M. Baum(2001). Secure Electronic Commerce (2nd ed). New York: Prentice-Hall.

Poblete, V. (1998). Fundamentos de Auditoría. Santiago: Editorial Gestión.

Román, M. (2005). Sociedad del Conocimiento y Refundación de la Escuela desde el Aula. Barcelona: Ventrosa Impresores.

SII (2006). Operación Renta 2006 marca récord de 97.04\% de declaraciones hechas por Internet. Servicio de Impuestos Internos. Extraído el 10 de agosto de 2006 desde: http://www.sii.cl/pagina/actualizada/noticias/2006/

Unit ed Nat ions (2005). Global E-Government Readiness Report 2005: From E-Government to E-Inclusion. New York: United Nations.

Valderrama, J. (1998). Teoría y Práctica de la Auditoría I. Madrid: Editorial Pirámide.

West, D. (2006). Global E-Government, 2006. Rhode Island: Center for Public Policy, Brown University.

$$
\text { (A) }
$$

